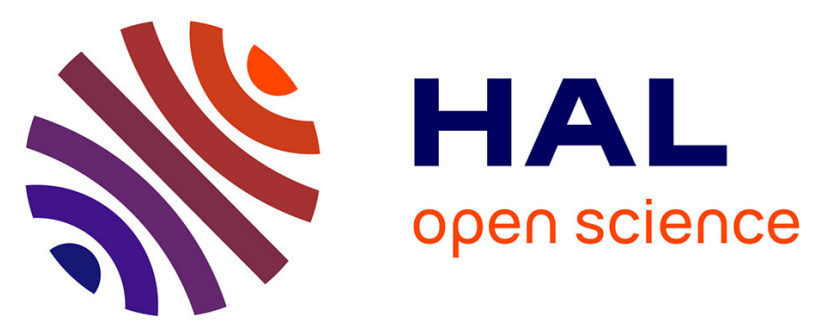

\title{
Linearly $\pi$-conjugated oligothiophenes as simple metal-free sensitizers for dye-sensitized solar cells
}

Dora Demeter, Jean Roncali, Siriporn Jungsuttiwong, Fabio Melchiorre, Paolo Biagini, Riccardo Po

\section{- To cite this version:}

Dora Demeter, Jean Roncali, Siriporn Jungsuttiwong, Fabio Melchiorre, Paolo Biagini, et al.. Linearly $\pi$-conjugated oligothiophenes as simple metal-free sensitizers for dye-sensitized solar cells. Journal of Materials Chemistry C, 2015, 3 (29), pp.7756-7761. 10.1039/c5tc01183c . hal-01391715

\section{HAL Id: hal-01391715 \\ https://hal.science/hal-01391715}

Submitted on 20 Sep 2021

HAL is a multi-disciplinary open access archive for the deposit and dissemination of scientific research documents, whether they are published or not. The documents may come from teaching and research institutions in France or abroad, or from public or private research centers.
L'archive ouverte pluridisciplinaire HAL, est destinée au dépôt et à la diffusion de documents scientifiques de niveau recherche, publiés ou non, émanant des établissements d'enseignement et de recherche français ou étrangers, des laboratoires publics ou privés.

\section{(c)(1)}

Distributed under a Creative Commons Attribution| 4.0 International License 


\title{
Linearly $\pi$-conjugated oligothiophenes as simple metal-free sensitizers for dye-sensitized solar cells $\dagger$
}

\author{
Dora Demeter, ${ }^{a}$ Jean Roncali, ${ }^{\star a}$ Siriporn Jungsuttiwong, ${ }^{\mathrm{b}}$ Fabio Melchiorre, ${ }^{c}$ \\ Paolo Biagini ${ }^{\star c}$ and Riccardo Po*c
}

Four linear oligothiophenes containing 4, 5 and 7 thiophene rings substituted by a variable number of octyl chains attached at the beta-position of some of the thiophene rings and possessing a terminal cyanoacrylic acid anchoring group have been synthesized. Results of UV-Vis absorption spectroscopy and cyclic voltammetry show that as expected the extension of the $\pi$-conjugated system leads to a decrease of the optical gap with an increase of the HOMO level. The four compounds have been evaluated as sensitizers in dye-sensitized solar cells (DSSCS) using a iodide/triiodide liquid electrolyte and the results are discussed in terms of the structureproperty relationship with regard to the extension of the conjugated system and the number and position of the octyl side chains using N719 as the reference system. A power conversion efficiency of $\sim 7.30 \%$ corresponding to $90 \%$ of the value given by N719 under identical conditions has been obtained with one of the heptamers.

\section{Introduction}

Dye-sensitized solar cells (DSSCs) based on nanocrystalline $\mathrm{TiO}_{2}$ have received considerable attention in the last two decades. ${ }^{1-9}$ Recently power conversion efficiencies (PCE) in the range of $12.0 \%$ have been reported, ${ }^{4,5}$ while prototypes and pre-commercial applications have been discussed. ${ }^{6}$ Although ruthenium(II) complexes have represented the archetype of sensitizers for almost two decades, ${ }^{1-3}$ recent years have witnessed the strong emergence of research on metal-free organic dyes. Interest in these compounds is motivated by simpler syntheses and purifications, lower cost and greater flexibility for the structural control of the energy levels and light-harvesting properties. ${ }^{7-9}$ Furthermore, metal-free chromophores can present high molar absorption coefficients thus allowing their use in thinner light-absorbing layers. During the past decade, a huge number of metal-free sensitizers have been synthesized and evaluated in DSSC cells and PCE exceeding $10.0 \%$ have been reported. ${ }^{9}$ On the other hand, some examples of cells combining metal-free chromophores and quantum dots have been published. ${ }^{11,12}$

Most of the metal-free sensitizers possess a D- $\pi$-A structure where " $\mathrm{D}$ " represents an electron-donating moiety such as a diarylamine or carbazole, " $\pi$ " a $\pi$-conjugating spacer and " $\mathrm{A}$ "

\footnotetext{
${ }^{a}$ Group Linear Conjugated Systems, CNRS Moltech-Anjou, University of Angers, 2Bd Lavoisier, 49045 Angers, France. E-mail: jeanroncali@gmail.com

${ }^{b}$ Center for Organic Electronics and Alternative Energies, Department of Chemistry, University of Ubon Ratchathani, Ubon Ratchathani, 34190, Thailand

${ }^{c}$ Centro Ricerche per le Energie Non Convenzionali, Istituto ENI Donegani, ENI S.p.A., via G. Fauser 4, 28100 Novara, Italy.E-mail: paolo.biabgini@eni.com
}

an electron-accepting moiety. In many cases A is a cyanoacrylic acid group to serve at the same time as an electron-withdrawing unit and an anchoring group on the $\mathrm{TiO}_{2}$ surface. ${ }^{7-10}$

Whereas many push-pull sensitizers based on this model have been synthesized, examples of sensitizers with a simple $\pi$-A structure namely devoid of terminal donor group remain scarce. $^{12-19}$ Thiophene oligomers (nTs) have been frequently used $\pi$-conjugating spacers in D- $\pi$-A sensitizers, ${ }^{7-9}$ but there are very few examples of sensitizers based on pure nTs. Thus, a PCE of 3.36\% was obtained with a quinquethiophene derivative with two carboxylic groups. ${ }^{12}$ DSSCs based on simple oligothiophenes with terminal carboxylic or cyanoacrylic acid anchoring groups have been described, ${ }^{13,14}$ while efficiencies of $\sim 5.0 \%$ have been obtained with sensitizers based on oligothiophenes with a terminal dithienothiophene unit. ${ }^{15}$ A PCE of $6.52 \%$ was reported for a cell based on a spiro-system and quaterthiophene with two anchoring groups. ${ }^{16}$ Very recently, a sensitizer based on a pentamer of 3-hexylthiophene was described and a PCE of $4.40 \%$ was reported for a solid-state DSSC. ${ }^{18}$ The latter result prompted us to publish the results of the work carried out independently in our laboratories on oligothiophene sensitizers. ${ }^{19}$

In this work, a series of oligothiophene chromophores involving four (4T), five (5T) and seven (7T) thiophene rings with terminal cyanoacrylic group have been synthesized. All oligomers contain octyl side chains in variable number and positions in order to provide appropriate solubility to the chromophore and contributing to prevent inter-chain aggregation. Two different thiophene heptamers have been synthesized that contain either two internal octyl chains on the terthienyl (3T) block (7Ti) or three octyl chains in a regio-regular arrangement (7Tr) (Fig. 1). 
47<smiles>[R]c1ccsc1-c1ccc(-c2cc([R])c(-c3ccc(/C=C(\C#N)C(=O)O)s3)s2)s1</smiles>

$$
\mathrm{R}=n-\text { Octyl }
$$

$5 \mathrm{~T}$<smiles>[R]c1ccsc1-c1cc([R])c(-c2ccc(-c3sc(-c4sc(/C=C(\C#N)C(=O)O)cc4[R])cc3[R])s2)s1</smiles>

$7 \mathrm{Ti}$

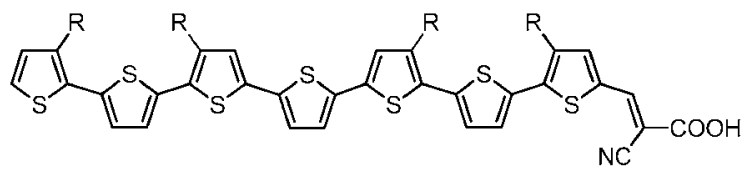

$7 \mathrm{Tr}$

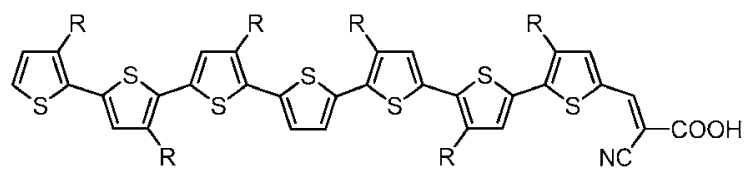

Fig. 1 Chemical structures of the oligothiophene sensitizers.

We describe the synthesis of the chromophores and the analysis of their electronic properties by cyclic voltammetry, UV-Vis spectroscopy and theoretical calculations. These new chromophores have been evaluated as sensitizers in DSSCs with iodide/triiodide-based conventional liquid electrolyte formulations. The results are discussed in terms of the structureproperty relationship with regard to the effects of the length of the $\pi$-conjugated system and the number and position of the octyl side-chains.

\section{Results and discussion}

\section{Synthesis}

3,4"-Dioctyl terthienyl (1a), 3,3', $4^{\prime \prime \prime}, 4^{\prime \prime \prime \prime}$-tetraoctyl-quinquethienyl (4a) and $3,3^{\prime}, 3^{\prime \prime} 4^{\prime \prime \prime \prime}, 4^{\prime \prime \prime \prime \prime}$-hexaoctyl-septithienyl (5a) have been synthesized according to already reported procedures. ${ }^{20}$ Bromination of terthienyl 1a with NBS gave the mono-bromo compound $\mathbf{1 b}$ in $63 \%$ yield. Lithiation of $1 \mathrm{a}$ with $n$-butyllithium and reaction with tributylstannyl chloride gave the Stille reagent $1 \mathrm{c}$ in quantitative yield (Fig. 2). A Stille coupling reaction between 1c and 2-bromo-5formyl thiophene (2) give the formyl-quaterthiophene 3 in $92 \%$ yield. Carboxaldehydes $\mathbf{4 b}$ and $\mathbf{5 b}$ were synthesized in $33 \%$ and $30 \%$ yields by Vilsmeier-Hack formylation of quinque- and septi-thienyl $4 \mathbf{a}$ and 5 a respectively. ${ }^{20,21}$

2,5-Distannyl-thiophene 6 was synthesized in quantitative yield from 2,5 dibromo-thiophene via a classical double lithiation/ stannylation. This reagent was then engaged in a double Stille coupling reaction to give septithienyl $7 \mathrm{a}$ in $47 \%$ yield. VilsmeierHack formylation of $7 \mathbf{a}$ gave the carboxaldehyde $7 \mathbf{b}$ in $34 \%$ yield. The target compounds were finally obtained by Knoevenagel condensation of carboxyaldehydes $\mathbf{3}, \mathbf{4 b}, \mathbf{5 b}$ and $\mathbf{7 b}$ with cyanoacetic acid in the presence of ammonium acetate to give the corresponding cyanoacids 4T, 5T, 7Tr and 7Ti in 53, 59, 57 and $66 \%$ yield respectively (see $\mathrm{ESI} \dagger$ ).

\section{Cyclic voltammetry}

Fig. 3 shows the oxidative cyclic voltammograms (CV) of the sensitizers in $\mathrm{CH}_{2} \mathrm{Cl}_{2}$ in the presence of tetrabutylammonium hexafluorophosphate as the supporting electrolyte. The CV of 4T shows a first quasi-reversible oxidation wave with an anodic peak potential $\left(E_{\mathrm{pa}}\right)$ at $1.04 \mathrm{~V}$ corresponding to the formation of the cation-radical (Table 1).

The occurrence of a broad cathodic wave on the reverse scan is indicative of a follow-up chemical reaction of the cationradical presumably associated to the formation of the dimer of 4T by coupling at the free $\alpha$-position. ${ }^{22}$ In contrast, the CV of the longer oligomers shows two successive reversible oxidation waves indicative of stable cation-radical and di-cation.

As expected, the extension of the oligothiophene chain produces a negative shift of $E_{\mathrm{pa}}$ from $1.04 \mathrm{~V}$ for $4 \mathrm{~T}$ to $0.75 \mathrm{~V}$ for $7 \mathrm{Tr}$. In the negative potential region, the $\mathrm{CV}$ of all compounds presents an irreversible reduction wave with a cathodic peak potential $\left(E_{\mathrm{pc}}\right)$ varying from $-0.91 \mathrm{~V}$ for dye $7 \mathrm{Ti}$ to $-1.06 \mathrm{~V}$ for dye $\mathbf{5 T}$.

\section{UV-Vis absorption spectroscopy}

Fig. 4 shows the UV-Vis absorption spectra of the target compounds in methylene chloride solution. The spectrum of the shortest dyes $\mathbf{4 T}$ and $\mathbf{5 T}$ presents a first absorption band with a maximum $\left(\lambda_{\max }\right)$ in the range $350-400 \mathrm{~nm}$ which shifts bathochromically with the extension of the conjugated system from 350 for 4 T to $c a$. $430 \mathrm{~nm}$ for $7 \mathbf{T i}$. These $\lambda_{\max }$ values are in good agreement with the absorption maxima reported for oligomers of 3-octylthiophene. ${ }^{23}$ This first band is followed by a second more intense band attributed to an internal charge transfer (ICT). The $\lambda_{\max }$ of this second band which is observed at ca. $480 \mathrm{~nm}$ for $\mathbf{4 T}$ and $\mathbf{5 T}$ presents an hypsochromic shift to 457 and $473 \mathrm{~nm}$ for $7 \mathbf{T r}$ and 7Ti. For these two septithiophenes the two transitions merge into a single broad band as confirmed by the large increase of FWHM (full width at half maximum) of the absorption band from $\sim 0.60 \mathrm{eV}$ for $4 \mathrm{~T}$ to $\sim 1.10 \mathrm{eV}$ for $7 \mathbf{T r}$ and 7Ti. These results show that whereas the $\lambda_{\max }$ of the first transition shifts bathochromically with chain extension, the maximum of the ICT and hence the optical HOMO-LUMO gap $(\Delta E)$ converge towards a limit (Table 1). This phenomenon suggests that, beyond a certain chain length, the lengthening of the conjugated chain does not produce any further increase the electron donor strength of the oligothiophene chain.

It is well known that the effective conjugation length (or energy gap) of all $\pi$-conjugated oligomers converges towards a limit for a chain length determined by structural factors such as bond length alternation, aromatic resonance energy and planarity. ${ }^{24,25}$ In this context, the above results suggest that in the specific case of the $\pi-\mathrm{A}$ oligomers discussed here, the maximum chain length effective for ICT is limited to $4-5$ thiophene units due to the rotational disorder inherent to oligothiophenes. Nevertheless, the fact that 7Ti absorbs at a longer wavelength than $7 \mathbf{T r}$ remains intriguing.

In order to gain further insight into this question the structures of different conformations of $7 \mathbf{T i}$ and $7 \mathbf{T r}$ have been investigated using DFT/B3LYP/6-31G(d,p) level of theory. 


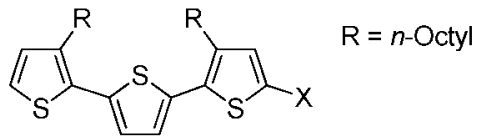

i)

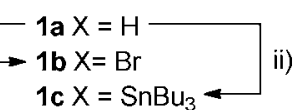

$1 c+$

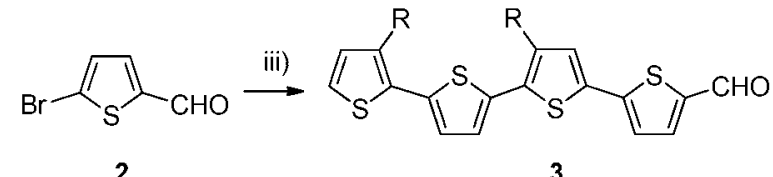

3<smiles>[X]c1cc([R])c(-c2cc([R])c(-c3cc([R])c(-c4cc([R])c(-c5ccc[Y4]5[H])s4)s3)s2)s1</smiles><smiles>[X]c1cc([R])c(-c2cc([R])c(-c3cc([R])c(-c4cc([R])c(-c5cc([R])c(-c6cc([R])c(-c7sccc7[R])s6)s5)s4)s3)s2)s1</smiles>

iv) $\begin{aligned} 5 \mathbf{a} X & =\mathrm{H} \\ 55 \mathbf{b} X & =\mathrm{CHO}\end{aligned}$

$1 \mathrm{~b}$
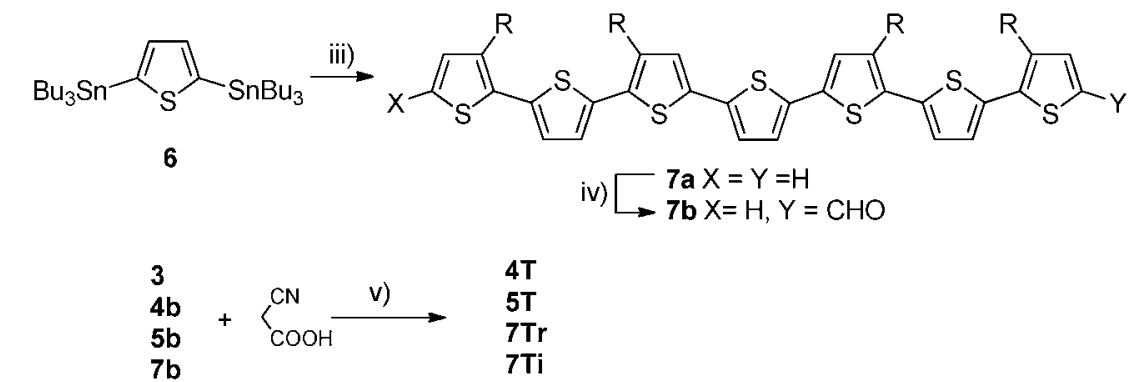

Fig. 2 Synthesis of the target compounds. (i) $\mathrm{NBS}, \mathrm{CHCl}_{3}$ /acetic acid (1:1); (ii) $n$-BuLi, $\mathrm{Bu}_{3} \mathrm{SnCl}$, THF; (iii) $\mathrm{Pd}\left(\mathrm{PPh}_{3}\right)_{4}$, toluene; (iv) DMF, POCl 3 , 1,2dichloroethane; (v) $\mathrm{NCCH}_{2} \mathrm{CO}_{2} \mathrm{H}$, ammonium acetate, glacial acetic acid.

Based on the above discussed limit of the effective chain length for ICT only a chain length of four thiophene rings has been considered for calculations and the absorption spectra of these systems have studied by TD-CAM-B3LYP/6-31G(d,p) level in $\mathrm{CH}_{2} \mathrm{Cl}_{2}$ as the solvent (see Fig. S5 and S6, ESI $\dagger$ ). Table 2 lists the calculated absorption maxima of the terminal $4 \mathrm{~T}$ fragment of $7 \mathrm{Tr}$ and 7Ti. The results show that for both dyes the anti-anti-anti conformation $(a-a-a)$ leads to the longest $\lambda_{\max }$ and hence smallest optical gap whereas the anti-syn-syn $(a-s-s)$ conformation leads to the most blue shifted $\lambda_{\max }$. However, comparison of the two series of data shows that for each conformation the 7Tr fragment absorbs at a shorter wavelength. Furthermore, the difference between the shortest and longest $\lambda_{\max }$ is of $37 \mathrm{~nm}$ for $7 \mathbf{T i}$ and increases to $51 \mathrm{~nm}$ for $7 \mathrm{Tr}$. If one considers that the conformation of oligothiophene molecules in solution is a statistical average of different rotational conformers these results suggest that in any case 7Ti should absorb at longer wavelengths.
Fig. 5 shows the UV-Vis absorption spectra of the four dyes adsorbed on nanoporous titanium dioxide films. These spectra agree well with the solution spectra of Fig. 4 and confirm that under these conditions 7Ti still absorbs at longer wavelengths than 7 Tr.

\section{Photovoltaic properties}

The performances of the four molecules as sensitizers have been investigated in DSSCs with liquid electrolytes (see ESI $\dagger$ ). Devices based on the well-known highly efficient ruthenium dye N719 were fabricated under the same conditions for comparison. Fig. 6 shows the current density vs. voltage curves of the various devices under AM 1.5 simulated solar illumination with a power light intensity of $100 \mathrm{~mW} \mathrm{~cm} \mathrm{~cm}^{-2}$ through a mask of $c a .10 \mathrm{~mm}^{2}$ aperture. Under these experimental conditions, the benchmark sensitizer N719 gives a short-circuit current density $\left(J_{\mathrm{sc}}\right)$ of $15.2 \mathrm{~mA} \mathrm{~cm}^{-2}$, an open-circuit voltage $\left(V_{\mathrm{oc}}\right)$ of $0.745 \mathrm{~V}$ and a 

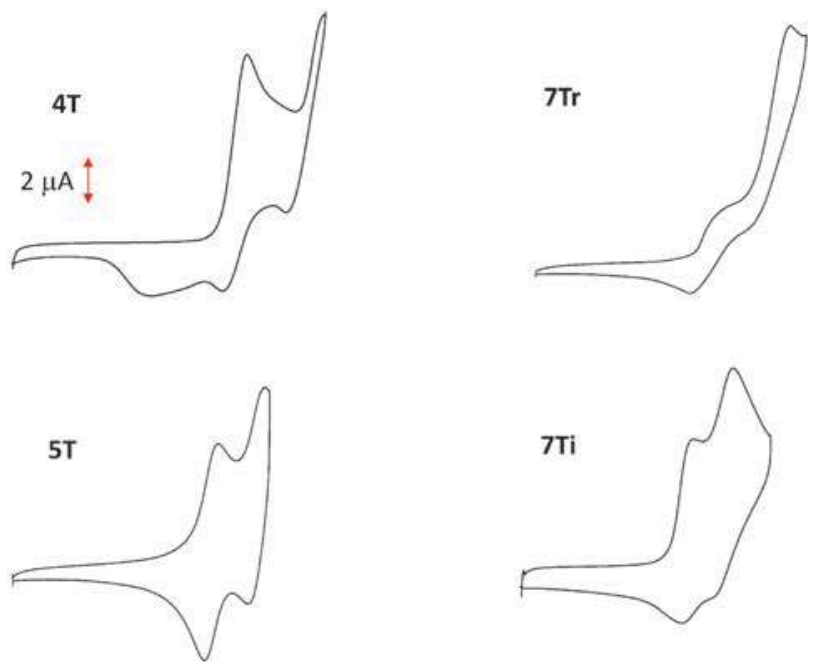

$\begin{array}{llllllllll}0.0 & 0.2 & 0.4 & 0.6 & 0.8 & 1.0 & 1.2\end{array}$

E [ V vs SCE]

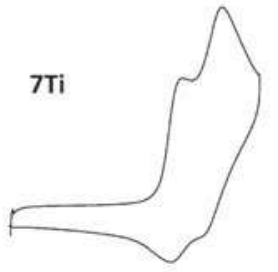

$\begin{array}{lllllllll}0.0 & 0.2 & 0.4 & 0.6 & 0.8 & 1.0 & 1.2\end{array}$ E [ V vs SCE]

Fig. 3 Cyclic voltammograms corresponding to the oxidation of oligothiophene sensitizers in $0.10 \mathrm{M} \mathrm{Bu}_{4} \mathrm{NPF}_{6} / \mathrm{CH}_{2} \mathrm{Cl}_{2}$, Pt electrodes, scan rate $100 \mathrm{mV} \mathrm{s}^{-1}$.

Table 1 Data of UV-Vis spectroscopy (in $\mathrm{CH}_{2} \mathrm{Cl}_{2}$ ) and cyclic voltammetry (in $0.10 \mathrm{M} \mathrm{Bu}_{4} \mathrm{NPF}_{6} / \mathrm{CH}_{2} \mathrm{Cl}_{2}$, scan rate $100 \mathrm{mV} \mathrm{s}{ }^{-1}$, Pt electrodes, ref. SCE) for the target compounds

\begin{tabular}{lcllllllll}
\hline & $\begin{array}{l}\lambda_{\max } \\
\text { Dye }\end{array}$ & $\begin{array}{l}\lambda_{\max , \mathrm{ICT}} \\
(\mathrm{nm})\end{array}$ & $\begin{array}{l}\Delta E^{a} \\
(\mathrm{eV})\end{array}$ & $\begin{array}{l}\varepsilon_{\max } \\
\left(\mathrm{M}^{-1} \mathrm{~cm}^{-1}\right)\end{array}$ & $\begin{array}{l}E_{\mathrm{pa}} \\
(\mathrm{V})\end{array}$ & $\begin{array}{l}E_{\mathrm{pc}} \\
(\mathrm{V})\end{array}$ & $\begin{array}{l}E_{\mathrm{HOMO}}{ }^{b} \\
(\mathrm{eV})\end{array}$ & $\begin{array}{l}E_{\mathrm{LUMO}}{ }^{c} \\
(\mathrm{eV})\end{array}$ \\
\hline $\mathbf{4 T}$ & 350 & 480 & 2.58 & 36000 & 1.04 & -1.01 & -5.78 & -3.20 \\
$\mathbf{5 T}$ & 372 & 479 & 2.59 & 35000 & 0.90 & -1.06 & -5.59 & -3.00 \\
7Tr & $400^{d}$ & 457 & 2.71 & 32000 & 0.75 & -0.95 & -5.54 & -2.83 \\
7Ti & $430^{d}$ & 473 & 2.62 & 35000 & 0.81 & -0.91 & -5.55 & -2.93
\end{tabular}

${ }^{a}$ based on the long wavelength absorption onset. ${ }^{b}$ using $E_{\mathrm{ox}}^{0}$ with an offset of $-4.99 \mathrm{eV}$ for SCE $v s$. the vacuum level. ${ }^{c}$ determined by $E_{\text {HOMO }}-\Delta E .^{d}$ Shoulder.

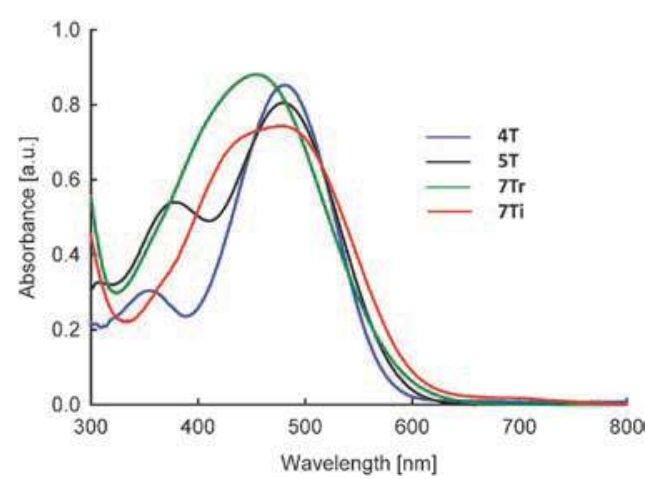

Fig. 4 UV-Vis absorption spectra of the oligothiophene sensitizers $\sim 2 \times$ $10^{-5} \mathrm{M}$ in methylene chloride solutions.

fill-factor (FF) of 0.72 leading to a power conversion efficiency (PCE) of $8.10 \%$ (Table 2). The results obtained with the four oligothiophene dyes show that the extension of the $\pi$-conjugated system from four to seven thiophenes leads to an marked increase of $J_{\mathrm{sc}}$ from 9.40 to $14.40 \mathrm{~mA} \mathrm{~cm} \mathrm{~cm}^{-2}$ together with a

Table 2 Calculated absorption maxima for various conformations of the end $4 \mathrm{~T}$ fragment of $7 \mathrm{Tr}$ and $\mathbf{7 T i}$
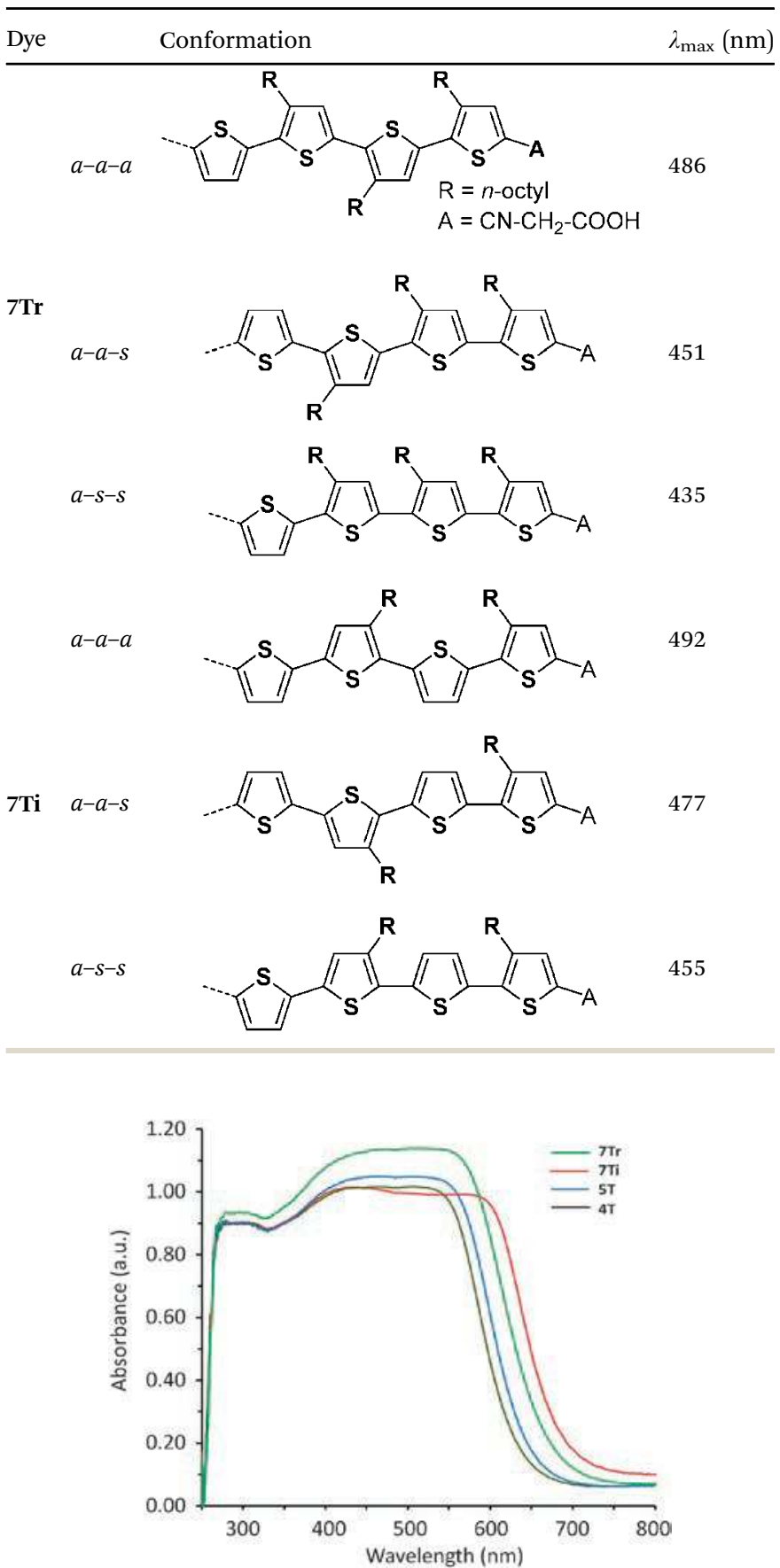

Fig. 5 UV-Vis absorption spectra of the sensitizers adsorbed on $\mathrm{TiO}_{2}$ films of ca. $8 \mu \mathrm{m}$ thickness.

ca. $200 \mathrm{mV}$ increase of $V_{\mathrm{oc}}$ values leading to PCE values comprised between 3.80 to $7.30 \%$.

The values of the fill factors are high $70-75 \%$ and independent of the structure of the sensitizer. The data in Table 3 show that the lengthening of the conjugated chain leads to an increase of $V_{\text {oc }}$. This result might be related to a decrease of charge recombination due to a better delocalization of the positive charge for the longer oligomers. Fig. 7 shows the external quantum efficiency (EQE) 


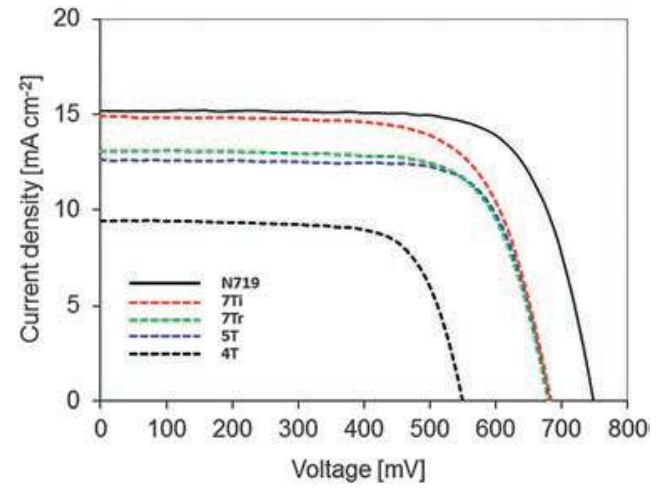

Fig. 6 Current-density vs. voltage for DSSCs based on oligothiophene sensitizers and N719 under AM 1.5 simulated solar illumination.

Table 3 Photovoltaic characteristics of the DSSC based on the oligothiophene sensitizers and N719 under SAM 1.5 simulated solar illumination. Data in bold are the best results obtained for each dye

\begin{tabular}{lllll}
\hline Dye & $J_{\text {sc }}\left(\mathrm{mA} \mathrm{cm}^{-2}\right)$ & $V_{\text {oc }}(\mathrm{V})$ & FF & PCE $(\%)$ \\
\hline 4T & 9.40 & 550 & 0.73 & 3.80 \\
& 8.80 & 553 & 0.72 & 3.60 \\
5T & 12.6 & & & \\
& 12.8 & 681 & 0.74 & 6.40 \\
& & 654 & 0.75 & 6.30 \\
7 Tr & $\mathbf{1 4 . 3}$ & 687 & 0.69 & 6.70 \\
& 13.7 & 665 & 0.72 & 6.50 \\
7 Ti & $\mathbf{1 4 . 4}$ & 708 & 0.71 & 7.30 \\
& 14.4 & 692 & 0.69 & 6.90 \\
N719 & $\mathbf{1 5 . 2}$ & 745 & 0.72 & $\mathbf{8 . 1 0}$ \\
& 15.0 & 727 & 0.73 & 8.00 \\
\hline
\end{tabular}

spectra of the various DSSCs. As expected the curves show that the extension of the conjugation length of the sensitizer produces a progressive bathochromic shift of the onset of photo-current from $\sim 650 \mathrm{~nm}$ for $4 \mathrm{~T}$ to $\sim 715 \mathrm{~nm}$ for $7 \mathrm{Ti}$ and $725 \mathrm{~nm}$ for the reference dye N719. The spectra also reveal a gradual increase of the photo-response which presents a broad plateau of $\sim 70 \%$ between 400 and $650 \mathrm{~nm}$ for $7 \mathrm{Ti}$.

The integration of the EQE response with respect to the solar irradiation spectrum leads to $J_{\mathrm{sc}}$ values corresponding to $85-90 \%$ of the values measured under white light illumination.

Comparison of the above results with the literature data on other oligothiophene sensitizers reported so far $^{13,19}$ shows that the new chromophores can lead to a significantly higher PCE with values reaching up to $90 \%$ of the efficiency of N719 in the case of $7 \mathrm{Ti}$. The increase of efficiency with chain length observed between $\mathbf{4 T}$ and $7 \mathbf{T}$ can be rationalized on the basis of the extension of the effective conjugation and reduced optical gap leading to better light-harvesting properties. On the other hand, the higher PCE values found for the cells based on 7Ti compared to $7 \mathrm{Tr}$ are consistent with UV-Vis absorption and theoretical results.

As a representative example, preliminary evaluation of the stability of the cells based on $7 \operatorname{Tr}$ under conditions similar to

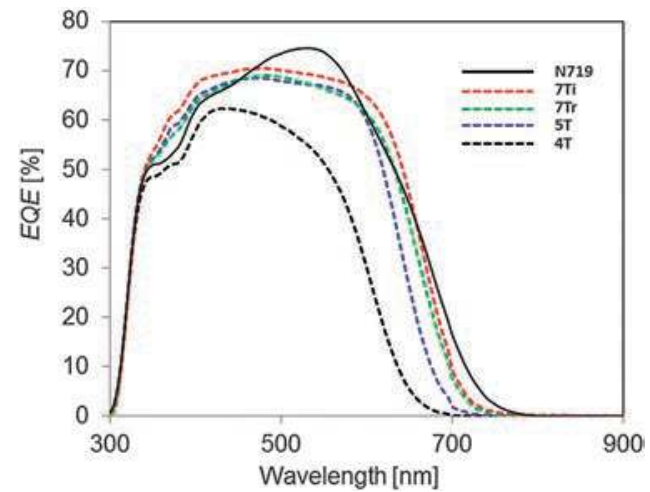

Fig. 7 External quantum efficiencies of the DSSCs based on oligothiophene sensitizers under monochromatic irradiation.

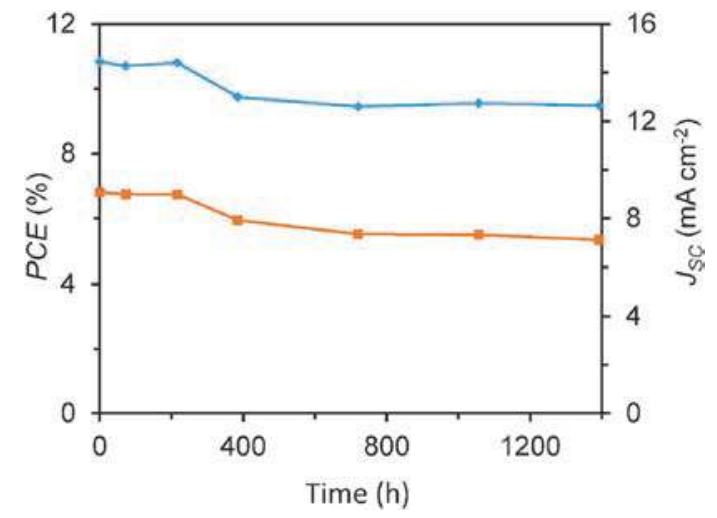

Fig. 8 Variation of the power conversion efficiency (red) and short-circuit current density (blue) for a DSSC cell based on 7Tr upon indoor storage under ambient conditions.

the ISOS-1 protocol developed for organic solar cells has been carried out. ${ }^{26}$ To this end the cells were aged at room temperature under indoor light and tested at regular time intervals. Fig. 8 shows the variation of PCE and $J_{\mathrm{sc}}$ during a period of two months. A first decrease of PCE of about $20 \%$ due to a corresponding decrease of $J_{\mathrm{sc}}$ is observed after $400 \mathrm{~h}$. However, no significant variation was observed in the following $800 \mathrm{~h}$. This result demonstrates the excellent stability of this $\pi-\mathrm{A}$ compound, even when combined with a conventional iodidetriiodide based electrolyte.

\section{Conclusion}

A series of chromophores based on oligothiophenes substituted by octyl chains with a terminal cyanoacrylic acid anchoring group have been synthesized. Optical and electrochemical results show that as expected, the extension of the $\pi$-conjugated system leads to a decrease of the optical gap with an increase of the HOMO level. These compounds have been evaluated under simulated solar illumination as sensitizers in DSSCs with diiode/iodide liquid electrolyte chains using N719 as the reference system. Although a general trend indicating an increase of efficiency with the length of the conjugated system is observed, the 
results obtained with the two heptamers reveal interesting differences that suggest that the number and position of the alkyl side chains play a major role in the control of both the conformation of the molecule and intermolecular interactions. These results suggest that in addition to light-harvesting properties, the design of sensitizers with a simple linearly $\pi$-conjugated structure should also take into account the structural control of intermolecular interactions in order to minimize chargerecombination and deactivation of the excited state through non-radiative intermolecular processes. Further work in this direction is now underway in our laboratories and will be reported in future publications.

\section{References}

1 B. O'Regan and M. Grätzel, Nature, 1991, 353, 737-740.

2 N. Robertson, Angew. Chem., Int. Ed., 2006, 45, 2338-2345.

3 A. Hagfeldt, G. Boschloo, L. Sun, L. Kloo and H. Pettersson, Chem. Rev., 2010, 110, 6595-6663.

4 A. Yella, H.-W. Lee, H. N. Tsao, C. Yi, A. K. Chandiran, M. K. Nazeeruddin, E. W.-G. Diau, C. Y. Yeh, S. M. Zakeeruddin and M. Grätzel, Science, 2011, 334, 629.

5 M. A. Green, K. Emery, Y. Hishikawa, W. Warta and E. D. Dunlop, Prog. Photovolt.: Res. Appl., 2014, 22, 1.

6 A. Fakharuddin, R. Jose, T. A. Brown, F. Fabregat-Santiago and J. Bisquert, Energy Environ. Sci., 2014, 7, 3952; Y. Wu and W. Zhu, Chem. Soc. Rev., 2013, 42, 2039.

7 Y.-S. Yen, H.-H. Chou, Y.-C. Chen, C.-Y. Hsu and J. T. Lin, J. Mater. Chem., 2012, 22, 8734.

8 M. Liang and J. Chen, Chem. Soc. Rev., 2013, 42, 3453.

9 J. Luo, M. Xu, R. Li, K. Huang, C. Jiang, Q. Qi, W. Zeng, J. Zhang, C. Chi, P. Wang and J. Wu, J. Am. Chem. Soc., 2014, 136, 265.

10 Y. Liu and J. Wang, Thin Solid Films, 2010, 518(24), e54.

11 C. Lelii, M. G. Bawendi, P. Biagini, P.-Y. Chen, M. Crucianelli, J. M. D'Arcy, F. De Angelis, P. T. Hammond and R. Po, J. Mater. Chem. A, 2014, 2, 18375.

12 S. Tan, J. Zhai, H. Fang, T. Jiu, J. Ge, Y. Li, L. Jiang and D. Zhu, Chem. - Eur. J., 2005, 11, 6272-6276.
13 K. Tanaka, K. Takimiya, T. Otsubo, K. Kawabuchi, S. Kajihara and Y. Harima, Chem. Lett., 2006, 35, 592.

14 E. Miyazaki, T. Okanishi, Y. Suzuki, N. Ishine, H. Mori, K. Takimiya and Y. Harima, Bull. Chem. Soc. Jpn., 2011, 84, 459.

15 H.-Y. Yang, Y.-S. Yen, Y.-C. Hsu, H.-H. Chou and J. T. Lin, Org. Lett., 2010, 12, 16.

16 H.-C. Ting, C.-H. Tsai, J.-H. Chen, L.-Y. Lin, S.-H. Chou, K.-T. Wong, T.-W. Huang and C.-C. Wu, Org. Lett., 2012, 14, 6338.

17 M. Urbani, E. M. Barea, R. Trevisan, A. Aljarilla, P. de la Cruz, J. Bisquert and F. Langa, Tetrahedron Lett., 2013, 54, 431.

18 A. Abate, M. Planells, D. J. Hollman, S. D. Stranks, A. Petrozza, A. R. S. Kandada, Y. Vaynzof, S. K. Pathak, N. Robertson and H. J. Snaith, Adv. Energy Mater., 2014, 4, 1400166.

19 P. Biagini, D. Demeter, P. Leriche, A. Pellegrino, J. Roncali and G. Schimperna, WO 2013160201A12012, (priority April 24th), assigned to ENI SpA and CNRS.

20 Y. Liu, J. Zhou, X. Wan and Y. Chen, Tetrahedron, 2009, 65, 5209.

21 D. Demeter, T. Rousseau, P. Leriche, T. Cauchy, R. Po and J. Roncali, Adv. Funct. Mater., 2011, 21, 4379.

22 J. Roncali, M. Giffard, M. Jubault and A. Gorgues, J. Electroanal. Chem., 1993, 361, 185.

23 G. Bidan, A. De Nicola, V. Enée and S. Guillerez, Chem. Mater., 1998, 10, 1052.

24 J. Roncali, Acc. Chem. Res., 2000, 33, 147.

25 J. Roncali, Chem. Rev., 1997, 97, 173.

26 M. O. Reese, S. A. Gevorgyan, M. Jørgensen, E. Bundgaard, S. R. Kurtz, D. S. Ginley, D. C. Olson, M. T. Lloyd, P. Morvillo, E. A. Katz, A. Elschner, O. Haillant, T. R. Currier, V. Shrotriya, M. Hermenau, M. Riede, K. R. Kirov, G. Trimmel, T. Rath, O. Inganäs, F. Zhang, M. Andersson, K. Tvingstedt, M. Lira-Cantu, D. Laird, C. McGuiness, S. Gowrisanker, M. Pannone, M. Xiao, J. Hauch, R. Steim, D. M. DeLongchamp, R. Rösch, H. Hoppe, N. Espinosa, A. Urbina, G. Yaman-Uzunoglu, J.-B. Bonekamp, A. J. J. M. van Breement, C. Girotto, E. Voroshazi and F. C. Krebs, Sol. Energy Mater. Sol. Cells, 2011, 95, 1253. 